\title{
Antioxidant activity of various plant extracts under ambient and accelerated storage of sunflower oil
}

\author{
By Farooq Anwar ${ }^{1 *}$, Amer Jamil ${ }^{1}$, Shahid Iqbal ${ }^{2}$ and Munir A. Sheikh ${ }^{1}$
}

\author{
${ }^{1}$ Department of Chemistry, University of Agriculture Faislabad-38040, Pakistan \\ ${ }^{2}$ Department of Chemistry, University of Sargodha, Sargodha-40100, Pakistan \\ ${ }^{*}$ Corresponding author: Dr. Farooq Anwar, Assistant Professor, Department of Chemistry, \\ University of Agriculture, Faisalabad-38040, Pakistan. Email: fanwarpk@yahoo.com
}

\section{RESUMEN}

Determinación mediante pruebas aceleradas y a temperatura ambiente de la actividad antioxidante de varios extractos de plantas en aceite de girasol.

El presente trabajo se ha realizado para investigar la capacidad antioxidante potencial de once plantas medicinales 0 económicamente importantes autónomas del Pakistán. Las plantas se extractaron con metanol al $80 \%$ y se estudia su capacidad antioxidante bajo diferentes condiciones de almacenamiento, utilizando aceite de girasol y soja como sustratos. Los ensayos previos de capacidad antioxidante se llevaron a cabo con la prueba TLC-test y midiendo el porcentaje de inhibición de la peroxidación del ácido linoleico. El rizoma de Iris germanica, las hojas de Lawsonia alba, y M. oleifera, las semillas de café (Coffee arabica), el salvado de arroz (Oryza sativa), el salvado de trigo y salvado, granos y cáscara de avena (Avenis sativa), que fueron las que tuvieron una mayor capacidad antioxidante, de todos los extractos, se ensayaron después usando los sustratos de girasol y soja. Los aceites vegetales se estabilizaron con una dosis de 0,12 (peso/peso) y se sometieron a ensayos de almacenamiento acelerados (15 días a $65^{\circ}$ ) o temperatura ambiente ( 6 meses). $\mathrm{E}$ deterioro oxidativo se siguió mediante la medida del índice de actividad (Al), índice de peróxido (PV), así como por el contenido de dienos y trienos. En general, los extractos de semillas de café, partículas y cáscaras de avena, y Iris germanica y hojas de $M$. oleifera fueron las que mostraron una mayor efectividad para extender la estabilidad de los aceites, y retardar la elevación del PV, así como en la prevención de la aparición de productos de oxidación primarios y secundarios. El orden de eficacia fue: partículas y cáscaras de avena > granos de café $>$ hojas de M. oleifera > Lawsonia alba > Iris germanica > salvado de arroz > salvado de trigo. Se detectaron diferencias significativas en el potencial antioxidante de algunos extractos tanto a temperatura ambiente como en condiciones de las pruebas aceleradas. Ello demostró una amplia gama de propiedades antioxidante de los extractos frente a los diferentes procedimientos analíticos empleados.

PALABRAS-CLAVE: Aceite de girasol - Actividad antioxidante - Extractos de plantas - Inhibición.

\section{SUMMARY}

Antioxidant activity of various plant extracts under ambient and accelerated storage of sunflower oil

The present study was conducted to investigate the antioxidant potential of 11 medicinally or economically important plant materials indigenous to Pakistan. The materials were extracted with $80 \%$ methanol and examined for their antioxidant activity under different storage conditions using sunflower and soybean oils as oxidation substrates. Preliminary antioxidant activity assessment among the extracts was conducted with the TLC-test and by measuring percent inhibition of linoleic acid peroxidation. The rhizome of Iris germanica, leaves of Lawsonia alba, and M. oleifera, coffee (Coffee arabica) beans, rice (Oryza sativa) bran, wheat bran and oats (Avenis sativa) groats and hull, which showed higher antioxidant activity among the extracts, were further evaluated using soybean and sunflower oils as oxidation substrates. The vegetable oils were stabilized with extracts at a dosage of $0.12 \%(\mathrm{w} / \mathrm{w})$, and individually subjected to accelerated $\left(65^{\circ} \mathrm{C}, 15\right.$ days) and ambient (6 months) storage. The oxidative deterioration level was monitored for the measurement of antioxidant activity index $(\mathrm{Al})$, peroxide value $(\mathrm{PV})$, conjugated dienes and trienes contents. Overall, the extracts of coffee beans, oat groats and hull, Iris germanica and M. oleifera leaves were found to be the most effective in extending oxidative stability, and retarding PV, primary and secondary oxidation products of soybean and sunflower oils. The order of efficiency of the plant extracts for stabilization of the subject oils was as follows: oat groats and hull $>$ coffee beans $>M$. oleifera leaves > Lawsonia alba > Iris germanica $>$ rice bran $>$ wheat bran. Significant differences in the antioxidant potential of some of the extracts for stabilization of substrate oils were observed under ambient and accelerated storage conditions and thus demonstrated a variable antioxidant prospective of the extracts under different analytical protocols.

KEY-WORDS: Antioxidant activity - Inhibition - Plant extracts - Sunflower oil.

\section{INTRODUCTION}

Lipid peroxidation in fats and fatty foods not only deteriorates their quality and brings about chemical spoilage, but also generates free radicals and reactive oxygen specieswhich are implicated in carcinogenesis, mutagenesis, inflammation, aging and cardiovascular diseases (Pezzuto and Park, 2002; Shahidi, 1997; Siddhuraju and Becker, 2003). Oxidative reactions limit the shelf-life of fresh and processed foodstuffs and are a serious concern in the vegetable oil and fat industry. Strongly oxidized oils could have toxic effects on human health and, therefore, these oils are not suitable for nutritive purposes because of reaction products (Kazuhisa, 2001; Farag et al., 1989). 
Synthetic antioxidants such as butylated hydroxyanisole (BHA), butylated hydroxyltoluene (BHT), and ter-butyl hydro quinone (TBHQ) are effective in the protection of unsaturated fats and oils and are, therefore, used as potential inhibitors of lipid peroxidation to stabilize fat-containing foodstuffs. However, the use of these synthetic antioxidants in foods is discouraged because of their toxicity and carcinogenicity (Shahidi, 1997; Jeong et al., 2004). Consequently, such antioxidants have been restricted recently, as they may cause liver swelling and influence liver enzyme activities (Siddhuraju and Becker, 2003).

Natural antioxidants are constituents of many fruits and vegetables, and they have attracted a great deal of public and scientific attention because of their anticarcinogenic potential and other healthpromoting effects. Recent epidemiological studies have indicated that diets rich in fruits and vegetables and those of selected natural antioxidants such as plant polyphenols, vitamin C and flavonoids are correlated with reduced incidence of cardiovascular and chronic diseases and of certain cancers (Siddhuraju and Becker, 2003; Zuo et al., 2002; Laandrault et al., 2001; Gheldof et al., 2003; Liu et al., 2000). Nowadays, when consumers are quite cautious about the quality of their diet and its chemical additives, there is an increasing interest on the part of the food industry and preventive medicine to replace synthetic antioxidants with those of safer, more natural origins. This has prompted the investigation and characterization of active natural antioxidant compounds in various plant-derived foods (Zuo et al., 2002). The fact that various antioxidants occur naturally in plants has been well proven (Pezzuto and Park, 2002; Bandoniene et al., 2000; Peterson, 2001; Wang et al., 2003; Gheldof et al., 2002). Some plants, especially rosemary and sage, other spices and some cereal extracts have been determined as promising sources of natural antioxidants. A number of in vitro and in vivo assays have been developed to measure the antioxidant activity of plant extracts (Wang et al., 2003; Gheldof et al., 2002). In this area, the assessment of the effectiveness of potential antioxidants, using vegetable oils and fats as oxidation substrates, has been the focus of intense research.

Economou et al., (1991) reported the antioxidant activity of some plant extracts of the Labiatae family in lard, stored at $75^{\circ} \mathrm{C}$. Metha et al., (1994) studied the antioxidant activity of the extract of ajowan seeds in an accelerated storage test using soybean oil. Bandoniene et al. (2000) evaluated the antioxidant activity of some selected plant extracts in rapeseed oil. The antioxidant effects of thyme in rapeseed oil, at $40{ }^{\circ} \mathrm{C}$, have also been reported by Wyen et al. (2000). Abdalla and Roozen (2001) investigated the antioxidant activity of sage and oregano in salad dressing. Jeong et al., (2004) studied the effects of heat treatment on the antioxidant activity of extracts from citrus peel. The antioxidant effects of some natural compounds have also been reported under microwave heating of vegetable oils (Yoshida and Takagi, 1991). A group of researchers at lowa State University has examined the antioxidant capacity of oat groat and hull extracts to inhibit the oxidation of vegetable oils at elevated temperatures (Peterson, 2001).

The measurement of antioxidant activity of plant extracts using vegetable oils as an oxidation substrate is usually a difficult task because oxidation at ambient or low temperature is a very slow process (Anwar et al., 2003a). Most of the studies reported so far in the literature, regarding the antioxidant potential of various plant extracts, have been conducted under the accelerated storage of vegetable oils. Literature reports revealed that plant extracts sometimes exhibit contradictory antioxidant activity when tested under different conditions and their effectiveness also depends on the substrate oil and oxidation tests (Economou et al., 1991). Therefore, it is important to understand how ambient and accelerated storage along with the nature of the substrate oil affects the efficiency of natural antioxidant extracts.

Pakistan is rich in medicinally important flora. Wide varieties of folk medicinal plants, growing on the fertile land of Pakistan, are unknowingly exploited and have not been scientifically investigated for their biologically active principles (Saleem et al., 2001). Although a significant number of these plant materials are in focus for drug discovery, and a wealth of information is available in the literature about their therapeutic applications, only a few of them have been collected from Pakistan and studied for their perceived antioxidant potential.

As the need for widely functional and safer natural antioxidants continues to exist, it is, therefore, imperative to measure the antioxidant activity of plant extracts under different analytical protocols. In this context, as a part of our preliminary studies (Anwar et al., 2003b) for assessing the antioxidant activity of indigenous plants and agro-materials, we have selected various plant organs and agricultural wastes from their natural habitat in Pakistan and examined their antioxidant potential. The ultimate objective of the present study was to design an analytical protocol and to predict the antioxidant activity of some known and some not so well-known indigenous plant materials, using different antioxidant assays under the accelerated and ambient storage of soybean and sunflower oils as oxidation substrates.

\section{MATERIALS AND METHODS}

Coffee beans (Coffee arabica) and the leaves of common basil (Ocimum basilicum) were collected from the botanical garden of PCSIR Labs. Complex, Karachi, Pakistan. Rhizome of Iris germanica and the leaves of Lawsonia alba were 
taken from their natural habitat in Pakistan. Rice (Oryza sativa) bran, wheat bran, guava (Psidium gugava) leaves, the fruit of Morus alba, citrus peel (Citrus reticulata) and oat (Avenis sativa) groats and hulls were obtained from local agricultural and industrial sources. Moringa oleifera leaves were collected from the mature plants in the vicinity of the University of Sindh, Jamshoro, Pakistan. All the plant organs/materials were further authenticated by consulting the standard Herbarium technique at the Department of Botany, University of Karachi, Karachi, Pakistan. Standards of BHA, BHT and linoleic acid were provided by Sigma Chemical Co. (St. Louis, MO). All other reagents and chemicals used were of E. Merck. Refined, bleached and deodorized (RBD) soybean oil (SBO) and sunflower oil (SFO), without additives or citric acid were obtained from the deodorization section of Wazir Ali Industries, Hyderabad, Pakistan. All the experimental work was carried out in glass equipment immersed in EDTA $(0.5 \% \mathrm{w} / \mathrm{v})$ for at least $24 \mathrm{~h}$, rinsed several times with deionized water and dried at $150{ }^{\circ} \mathrm{C}$ before use.

\subsection{Extraction of Plant Materials}

The collected plant materials and agricultural wastes were air dried under shade at ambient temperature and ground to pass a $1 \mathrm{~mm}$ sieve. The ground materials $(0.2 \mathrm{~g})$ were extracted with $40 \mathrm{~mL}$ of $80 \%$ methanol in a sonication bath for $1 \mathrm{~h}$ followed by centrifugation for $10 \mathrm{~min}$ at $3800 \times \mathrm{g}$. The pellets were extracted twice with $40 \mathrm{ml}$ of $80 \%$ methanol and the extracts were evaporated to dryness under reduced pressure at $45^{\circ} \mathrm{C}$ using a rotary evaporator (EYELA, Rotary Vacuum Evaporator N. N. Series equipped with an Aspirator and a Digital Water Bath SB-651, Japan) and stored under refrigeration $\left(-18{ }^{\circ} \mathrm{C}\right)$ until used for further analyses.

\subsection{Preliminary Evaluation of Antioxidant Activity among the Extracts}

\subsubsection{Antioxidant Activity Evaluation by Thin-Layer Chromatography (TLC)}

Rapid evaluation of antioxidant activity of the extracts was done following a reported procedure as adopted by Metha et al., (1994). Briefly, thin layer chromatographic plates $(0.25 \mathrm{~mm})$, activated at 100 ${ }^{\circ} \mathrm{C}$ for $1 \mathrm{~h}$, and precoated with silica gel $\mathrm{G}$ were streaked with $200 \mu \mathrm{L}$ of each of the crude concentrated extracts and developed using a mixture of solvents of chloroform/ethanol/acetic acid (98:2:2). Plates were sprayed with a solution (9 $\mathrm{mg}$ of $\beta$-carotene dissolved in $30 \mathrm{~mL}$ of chloroform, to which 2 drops of linoleic acid and $60 \mathrm{~mL}$ of ethanol were added) and exposed to daylight for 6 h. The intensity of the resulting orange color, as measured by a TLC scanner, corresponded to the relative antioxidant activity of the extracts.

\subsubsection{Determination of Antioxidant Activity in Linoleic Acid System}

The antioxidant activity of the extracts was determined according to the method of Osawa and Namiki (1981). Extracts (5 mg) of each sample were added to a solution mixture of linoleic acid ( 0.13 $\mathrm{mL}), 99.8 \%$ ethanol $(10 \mathrm{~mL})$, and $0.2 \mathrm{M}$ sodium phosphate buffer ( $\mathrm{pH}$ 7.0). The total volume was adjusted to $25 \mathrm{~mL}$ with distilled water. The solution was incubated at $40^{\circ} \mathrm{C}$, and the degree of oxidation was measured according to the thiocyanate method (Mitsuda et al., 1966), with $10 \mathrm{~mL}$ of ethanol (75\%), $0.2 \mathrm{~mL}$ of an aqueous solution of ammonium thiocyanate (30\%), $0.2 \mathrm{~mL}$ sample solution, and 0.2 $\mathrm{mL}$ of ferrous chloride $\left(\mathrm{FeCl}_{2}\right)$ solution $(20 \mathrm{mM}$ in $3.5 \% \mathrm{HCl}$ ) being added sequentially. After $3 \mathrm{~min}$ of stirring, the absorption values of mixtures measured at $500 \mathrm{~nm}$ were taken as peroxide contents. A control was performed with linoleic acid but without extracts. Synthetic antioxidants i.e. $\mathrm{BHA}, \mathrm{BHT}$ were used as a positive control. The maximum peroxidation level was observed at $312 \mathrm{~h}$ in the sample that did not have any antioxidant extract and was used as a test point. The percent inhibition of linoleic acid peroxidation, 100 - [Abs. increase of sample at $312 \mathrm{~h} / \mathrm{Abs}$. increase of control at 312 h) $\times 100$ ], was calculated to express antioxidative activity.

\subsection{Determination of Antioxidant Activity using SBO and SFO as Oxidation Substrates}

\subsubsection{Stabilization of Oil Samples}

The crude concentrated extracts, which showed relatively high antioxidant activity among the eleven extracts in TLC and linoleic acid peroxidation system (at a level of $0.12 \%$ ) (w/w), were individually added to pre-heated RBD soybean and sunflower oils. The mixtures were stirred for $30 \mathrm{~min}$. at $50{ }^{\circ} \mathrm{C}$ for uniform dispersion. A control (without the addition of any antioxidant extract) was also prepared for each of the soybean and sunflower oil treatments and stored under the same conditions.

\subsubsection{Ambient and Accelerated Storage of Oils and Measurement of the Extent of Oxidation}

Three replicates for each of the soybean and sunflower oil treatments along with controls were carried out. In accelerated (oven) storage tests, the samples were stored at controlled temperatures of $65{ }^{\circ} \mathrm{C}$ in an oven for 15 days, whereas in the ambientstorage tests, the samples were stored for a period of six months at room temperature. The oxidative deterioration level was monitored for the measurement of antioxidant activity index (AI), peroxide value (PV), conjugated dienes (CD) and conjugated trienes (CT) contents. The analyses 
were carried out periodically after every three days and after thirty days for oven stored and ambient stored samples, respectively.

Determination of PV was made according the IUPAC standard method (IUPAC, 1987). Specific extinctions at 232 and $268 \mathrm{~nm}$ were determined using a Perkin-Elmer, model Lambda 2 spectrometer. Samples were diluted with iso-octane to bring the absorbance within limits (0.2-0.8) and $\left({ }^{1 \%} \varepsilon_{1 \mathrm{~cm}(\lambda)}\right)$ was calculated following the method of IUPAC (1987).

Determination of the induction period (IP) and thus calculation of $\mathrm{Al}$ was made following the procedure of Metrohm Application Bulletin (Metrohm Application Bulletin, 1993). An automated Metrohm Rancimat Model 679, capable of operating over a temperature range of $50-200^{\circ} \mathrm{C}$, was used for the determination of the induction periods (IP) of stabilized and controlled oil treatments. Analysis was carried out at $120 \pm 0.1{ }^{\circ} \mathrm{C}$ and oxidative stability was measured following the procedure described elsewhere (Anwar et al., 2003). Briefly, oil $(2.5 \mathrm{~g})$ was carefully weighed into each of the six reaction vessels and analyzed simultaneously. The IP of the samples was automatically recorded and corresponded to the break point of the plotted curves.

\section{RESULTS AND DISCUSSION}

Legend keys for the identification of different soybean and sunflower oil treatments are shown in Table 1 as Series 1 and Series 2. Results of various antioxidant assays and the predictor of antioxidant properties of extracts are shown in different figures. The whole data are the mean of duplicate samples, each sample analyzed in triplicate $(n=2 \times 3)$. In TLC assay, methanolic extracts (ME) of oat, groats and hull exhibited the highest intensity of resulting orange color which might be attributed to the presence of a high amount of phenolic compounds. On the basis of TLC assay, antioxidant activity of the investigated plant extracts followed the order; oat groats and hull (og) > coffee beans $(\mathrm{cb})>$ Moringa oleifera $(\mathrm{mo})>$ Iris germanica (ig) > Lawsonia alba (la) > rice bran (rb) > wheat bran (wb) > Morus alba (ma) > citrus peel (cp) > Ocimum basilicum (ob) > guava leaves (gl). These findings are further supported by the work of Peterson (2001) and Emmons and Peterson (1999); who described oat groat and hull, a rich source of phenolics and avenanthramides, which are well known to act as good natural antioxidants.

Extracts of various plant organs also exhibited good antioxidant activity in the linoleic acid peroxidation system as shown in Fig. 1. Four of the

Table 1

Identification of Oil Treatments

\begin{tabular}{ll}
\hline Series-1 & \multicolumn{1}{c}{ Soybean Oil (SBO) Treatments } \\
\hline SBO-c & Soybean oil without any extract (control) \\
SBO-og & Soybean oil treated with methanolic extract (ME) of oat groats \& hull (og) \\
SBO-ig & Soybean oil treated with ME of rhizome of Iris germanica (ig) \\
SBO-la & Soybean oil treated with (ME) of leaves of Lawsonia alba (la) \\
SBO-cb & Soybean oil treated with ME of coffee beans (cb) \\
SBO-rb & Soybean oil treated with ME of rice bran (rb) \\
SBO-gl & Soybean oil treated with ME of guava leaves (gl) \\
SBO-wb & Soybean oil treated with ME of wheat bran (wb) \\
SBO-mo & Soybean oil treated with ME of Moringa oleifera (mo) leaves \\
SBO-ma & Soybean oil treated with ME of fruit of Morus alba (ma) \\
SBO-cp & Soybean oil treated with ME of citrus peel (cp) \\
SBO-ob & Soybean oil treated with ME of Ocimum basilicium (ob) \\
\hline Series-2 & \\
\hline SFO-c & Sunflower oil without any extract (control) \\
SFO-og & Sunflower oil treated with ME of oat groats and hull (og) \\
SFO-ig & Sunflower oil treated with ME of rhizome of Iris germanica (ig) \\
SFO-la & Sunflower oil treated with ME of leaves of Lawsonia alba (la) \\
SFO-cb & Sunflower oil treated with ME of coffee beans (cb) \\
SFO-rb & Sunflower oil treated with ME of rice bran (rb) \\
SFO-gl & Sunflower oil treated with ME of guava leaves (gl) \\
SFO-wb & Sunflower oil treated with ME of wheat bran (wb) \\
SFO-mo & Sunflower oil treated with ME of Moringa oleifera leaves (mo) \\
SFO-ma & Sunflower oil treated with ME of fruit of Morus alba(ma) \\
SFO-cp & Sunflower oil treated with ME of citrus peel (cp) \\
SFO-ob & Sunflower oil treated with ME of Ocimum basilicium(ob) \\
\hline &
\end{tabular}




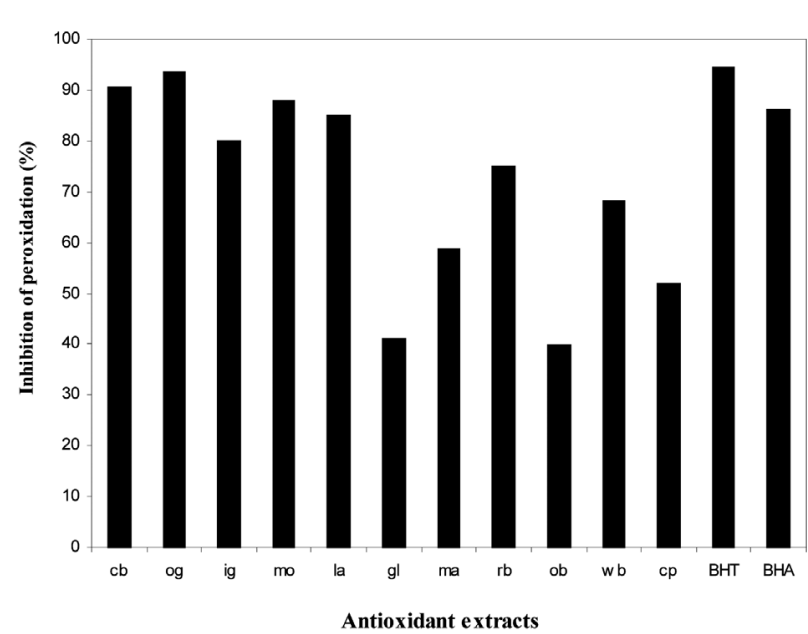

Figure 1

Antioxidant Activity of Various Plant Extracts in Linoleic acid Peroxidation System

extracts namely; cb, mo, og and la at a concentration of $0.2 \mathrm{mg} / \mathrm{mL}$ inhibited $85-93.5 \%$ peroxidation of linoleic acid after incubation of 13 days (312 h). This percentage was quite comparable to that of the values obtained for BHT (94.5\%) and BHA (86\%), and differences were statistically non-significant $(\mathrm{p}<$ 0.05 ). The inhibition of peroxidation was found to be $80.0,74.8,68 \%$ for the extracts of ig, rb and wb respectively; demonstrating moderate antioxidant activity. However, the extracts of ma, cp, gl, wb and ob (inhibition of peroxidation 39.7\%-68.0\%) exhibited noticeably lower antioxidant activity than those of other plant extracts and synthetic antioxidants. The differences in the inhibition of peroxidation, as exhibited by different extracts, might be attributed to the varying amounts of antioxidant substances. While higher antioxidant activity of the methanolic extracts of og, cb, mo and la may be attributed to a higher concentration of the constituent flavonoids, ferulic, gallic and caffeic acid derivatives, avenanthramides, and other phenolics. Velioglue et al. (1998) have reported that the total phenolic content of various fruits and vegetables contained potential antioxidant activities against the linoleic acid peroxidation system.

The antioxidant activity indexes (Al) of seven selected plant extracts, using soybean and sunflower oils as oxidation substrates have been shown in Fig. $2 \mathrm{a}, 2 \mathrm{~b}$ respectively. $\mathrm{Al}$ is an important criterion for the evaluation of the effectiveness of antioxidants (Metrohm Application Bulletin, 1993). It is evident from Fig. $2 a$, and $2 b$ that the addition of antioxidant extracts of plants has significantly enhanced the $\mathrm{Al}$ values of SBO and SFO treatments. The Al value of the control (oil sample without any extract) was quite low and thus showed the least oxidative stability among all the oil treatments. ME of og (Al; 3.75, 3.15), cb (Al; 3.40, 2.90) $\mathrm{mo}(\mathrm{Al} ; 3.15,2.7)$ and la (Al; 2.95, 2.57) exhibited the highest antioxidant activities as noted by the $\mathrm{Al}$ values of SBO and SFO treatments respectively. These results of $\mathrm{Al}$ are in agreement
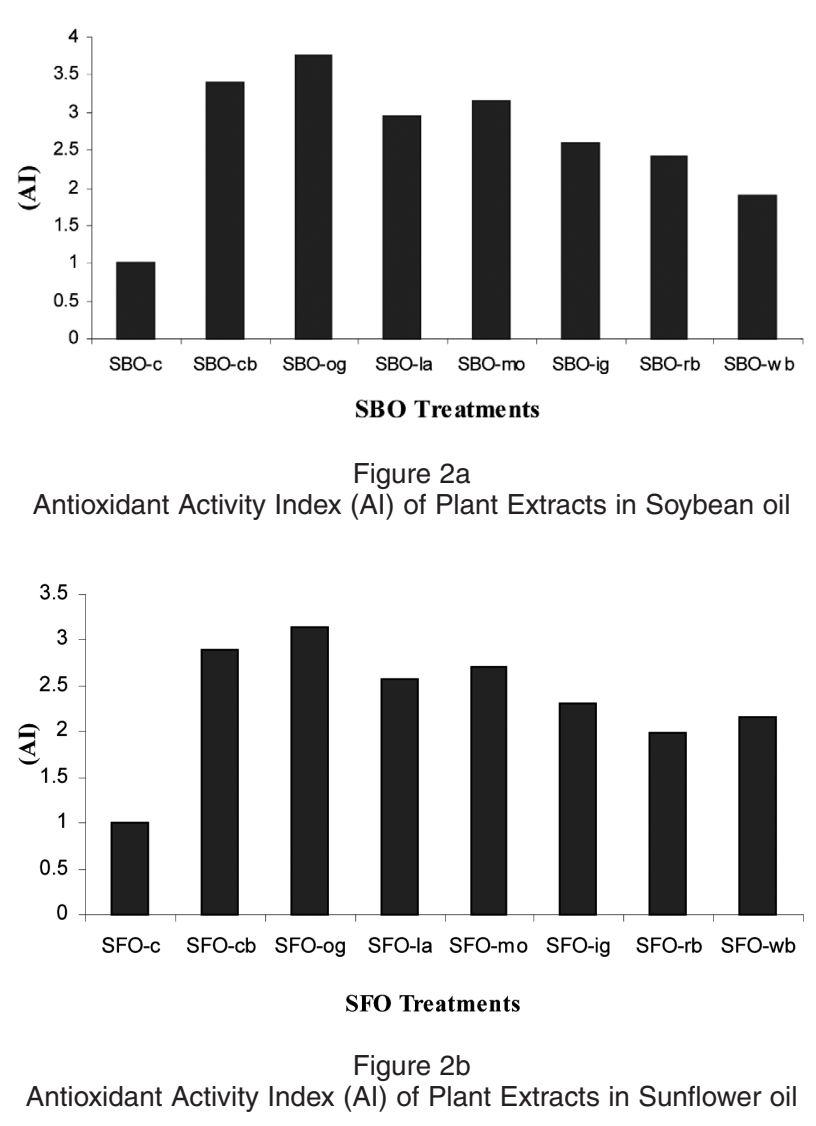

with those of TLC and inhibition of peroxidation assays. Al values suggest that rice bran, wheat bran and guava leave extracts, are relatively less effective sources of antioxidants.

Fig. $3 a, 3 b$ shows the relative increase in peroxide value (PV) of SBO treatments under accelerated $\left(15\right.$ days at $65^{\circ} \mathrm{C}$ ) and ambient (room temp. 6 months) storage respectively. The peroxide value, which measures hydroperoxide products of the oils (Mc Ginely, 1991), is a good indicator of the oxidation state of the oils. A typical pattern in the rise of $\mathrm{PV}$ was observed for almost all the oil treatments under both storage conditions. The control had the highest PV (accelerated storage, 85.0; ambient storage, $6.40 \mathrm{meq} / \mathrm{kg}$ ) among all the oil treatments, showing a higher degree of oxidation. Through methanolic extract, oat groats, coffee beans and Moringa oleifera leaves were found to be the most

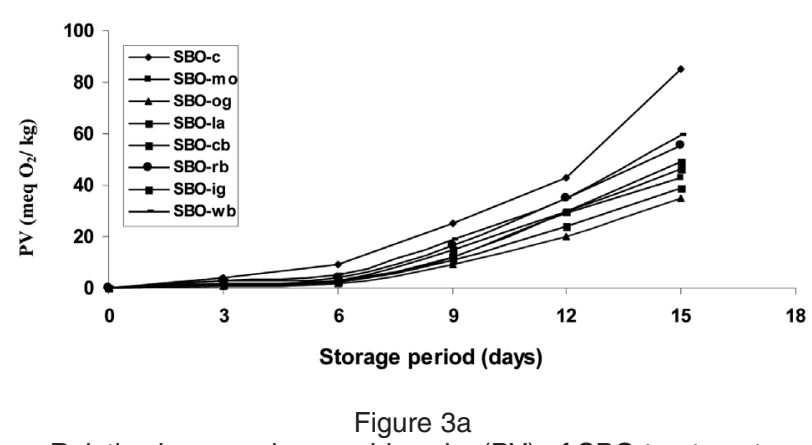

Relative increase in peroxide value(PV) of SBO treatments under accelerated storage 


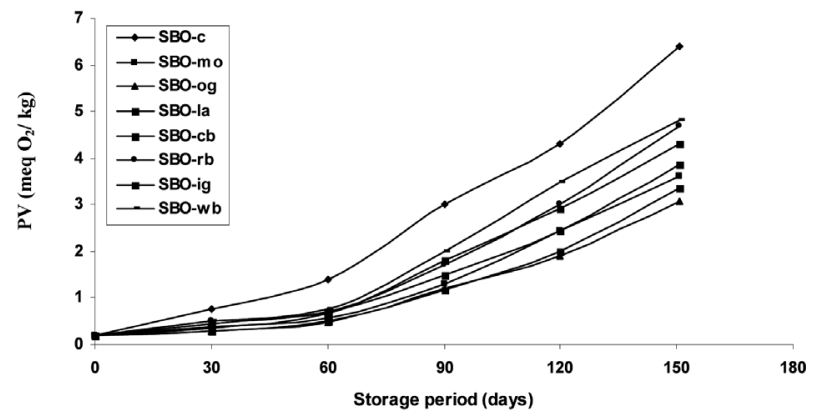

Figure 3b

Relative increase in peroxide value(PV) of SBO treatments under ambient storage

effective in retarding the PV of soybean oil treatments, whereas, others were relatively less effective. A slow rise in the PV of most of the oil treatments, as compared to those of the control, clearly indicated a good antioxidant activity of the extracts. The relative increase in the PV of SFO treatments, during accelerated and ambient storage is shown in Fig. $4 a, 4 b$ respectively. The control had the highest PV among the treatments, indicating the highest intensity of oxidation. A significantly lower PV than the control in SFO-og, SFO-cb, SFO-mo, under both sets of storage conditions, indicated a higher antioxidant activity of oat groats, coffee beans and $M$. oleifera leaves. The order of stabilization of these extracts was comparable for

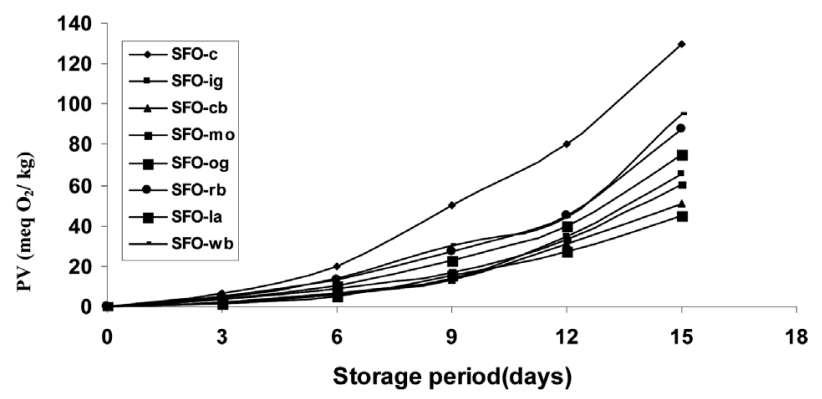

Figure $4 a$

Relative increase in peroxide value (PV) of SFO treatments under accelerated storage

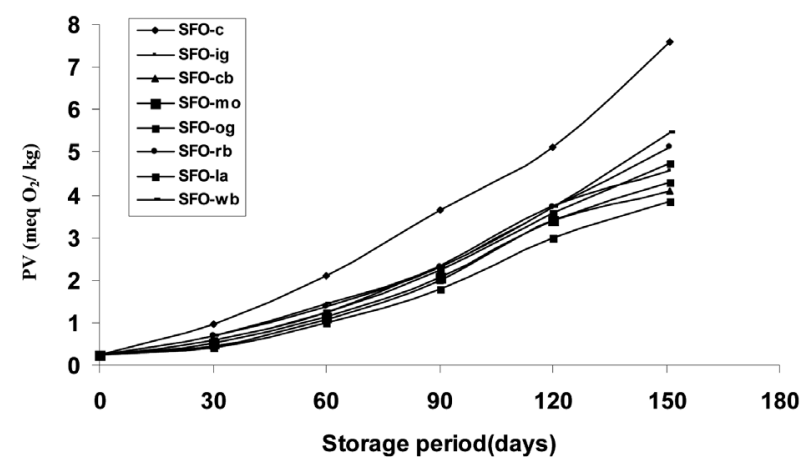

Figure 4b

Relative increase in peroxide value (PV) of SFO treatments under ambient storage both SFO and SBO treatments under all conditions. However, the antioxidant activity of Lawsonia alba, as revealed by SFO treatments, was not agreeable with that of SBO treatments.

The specific extinctions, in terms of conjugated dienes (CD) at 232nm and conjugated trienes (CT) at $268 \mathrm{~nm}$ are considered important parameters for the investigation of oxidative deterioration of the oils (Yoon, 1985) and thus a good indicator of the antioxidant effectiveness of the antioxidant extracts. Fig. $5 \mathrm{a}, 5 \mathrm{~b}$ show the relative increase in the content of conjugated dienes (CD), under ambient and accelerated storage respectively for SBO treatments. A slow, followed by a sharp order of increase in the contents of $C D$ was observed in almost all the oil treatments under both sets of storage conditions. The highest rise in CD was observed for the control as compared to those of other oil treatments. Coffee beans, Iris germanica and oat groats and hull provided the most effective extracts in retarding the formation of CD under accelerated and ambient storage of soybean oil and thus showed a higher antioxidant potential among the extracts. However, it was noted that the antioxidant capacity of rice bran extract was variable in the same substrate oil, under different storage conditions. In contrast to the previously exhibited higher antioxidant activity of rice bran extract than wheat bran, under accelerated storage of SBO, the latter was found to be more effective than the former in retarding $C D$ formation under ambient storage of SBO.

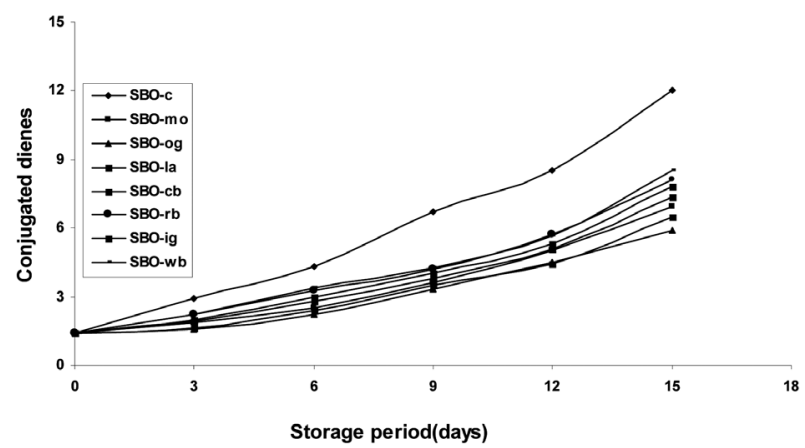

Figure $5 a$

Relative increase in conjugated dienes $\left({ }^{1 \%} \mathcal{E}_{1 \mathrm{~cm}}\left(\lambda_{232 \mathrm{~nm}}\right)\right.$ of SBO treatments under accelerated storage conditions

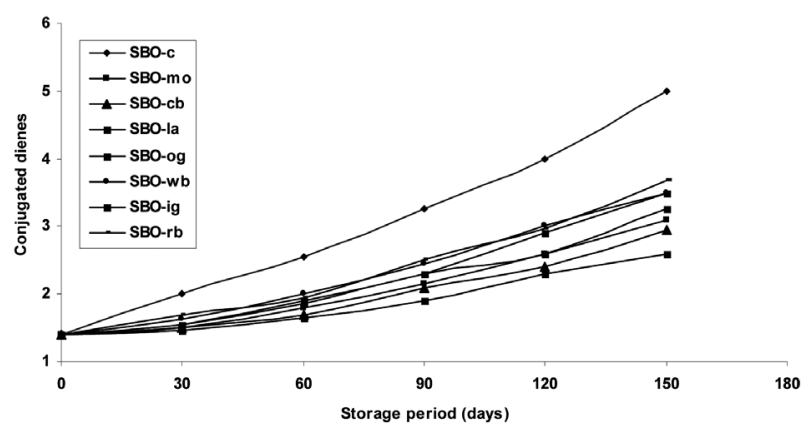

Figure 5b

Relative increase in conjugated dienes $\left({ }^{1 \%} \varepsilon_{1 \mathrm{~cm}}\left(\lambda_{232 \mathrm{~nm}}\right)\right.$ of SBO treatments under ambient storage conditions 
Fig. $6 \mathrm{a}, 6 \mathrm{~b}$ show the relative increase in $C D$ contents of SFO treatments under accelerated and ambient storage, respectively. The control exhibited the highest CD contents among the treatments under both sets of storage conditions, suggesting a higher intensity of oxidation. The CD values for the stabilized SFO treatments were lower as compared to the control revealing good antioxidant activity of the extracts. The extracts of coffee beans, oat groats and hulls and Moringa oleifera, exhibited the highest antioxidant activity. However, there was a marked variation in the effectiveness of coffee bean extract, which in contrast to its earlier activity was noted to be more effective than oat groats and hulls in SFO treatments under both accelerated and ambient storage. Moreover, under ambient storage of SFO, the antioxidant activity of Iris germanica was higher than Lawsonia alba, which was contradictory to its activity under accelerated incubation of the same oil.

The relative increase in conjugated trienes (CT) content, under accelerated and ambient storage of SBO treatments is shown in Fig. 7a, 7b, respectively. The CT is also a good indicator of the degree of oxidative deterioration of the oils (Yoon et al., 1985) and thus a measurement of antioxidant activity of the extracts. The control showed higher CT among all the SBO treatments under both conditions of storage and thus indicated the highest degree of oxidation. The contents of CT for SBO-og, SBO-cb, SBO-mo were quite low as compared to those of other SBO treatments, which clearly

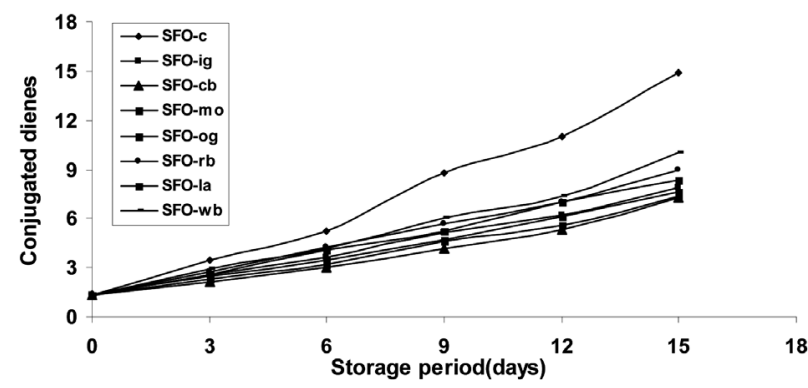

Figure 6a

Relative increase in conjugated dienes $\left({ }^{1 \%} \varepsilon_{1 \mathrm{~cm}}\left(\lambda_{232 \mathrm{~nm}}\right)\right.$ of SFO treatments under accelerated storage conditions

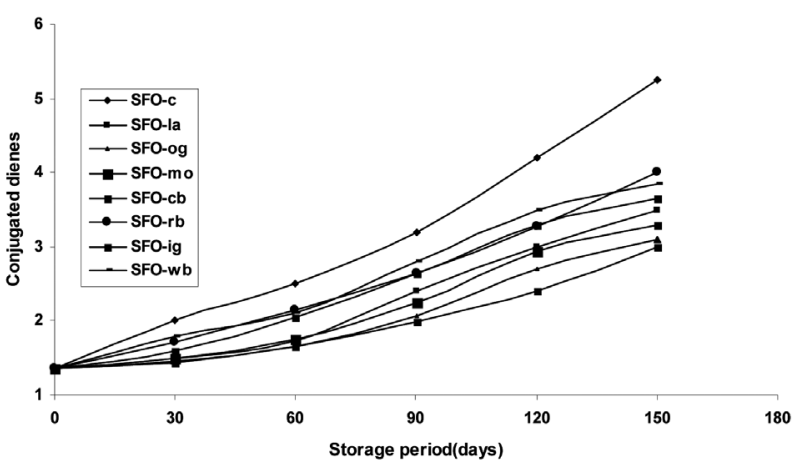

Figure $6 b$

Relative increase in conjugated dienes $\left({ }^{1 \%} \varepsilon_{1 \mathrm{~cm}}\left(\lambda_{232 n \mathrm{~m}}\right)\right.$ of SFO treatments under ambient storage conditions

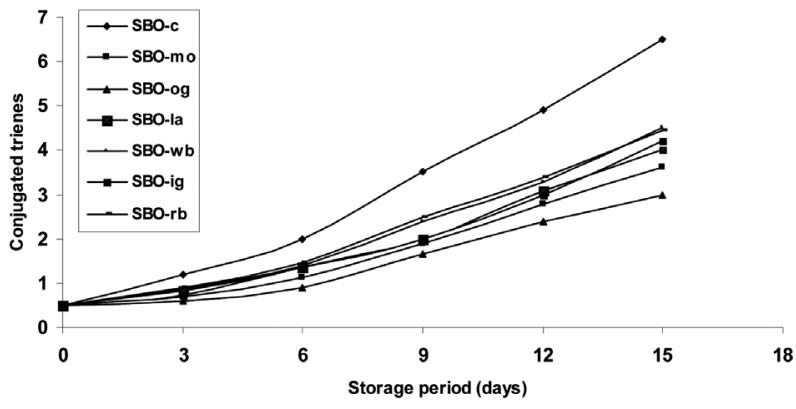

Figure $7 a$

Relative increase in conjugated trienes $\left({ }^{1 \%} \varepsilon_{1 \mathrm{~cm}}\left(\lambda_{268 \mathrm{~nm}}\right)\right.$ of SBO treatments under accelerated storage conditions

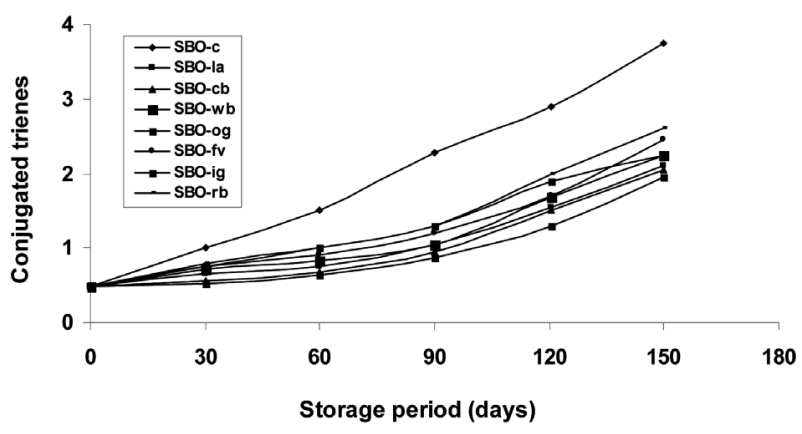

Figure $7 b$

Relative increase in conjugated trienes $\left({ }^{1 \%} \varepsilon_{1 \mathrm{~cm}}\left(\lambda_{268 \mathrm{~nm}}\right)\right.$ of SBO treatments under ambient storage conditions

reflected the higher antioxidant potential of oat groats, coffee beans and Moringa oleifera extracts. However, there was variation in the effectiveness of some other extracts as measured by CT content, under both accelerated and ambient storage of oils. In retarding the formation of $\mathrm{CT}$, wheat bran extract was found to be more effective than rice bran, the latter had previously shown higher antioxidant activity than the former in retarding the formation of peroxides and $C D$, even in the same substrate oil.

Fig $8 a, 8 b$ show the relative increase in conjugated trienes (CT) content of SFO treatments under accelerated and ambient storage, respectively. It is evident from the values of CT that under both sets of storage conditions, the extracts of oat groats, coffee beans, Moringa oleifera and Lawsonia alba, have higher antioxidant activity. However, there was notable variation in the activity of extracts of Moringa oleifera and Lawsonia alba, which intended to be more effective in retarding the formation of CT under ambient storage of oil, and thus reflecting a contradictory antioxidant activity to that previously projected during measurement of $\mathrm{Al}$, PV and CD of the same substrate oil.

In the light of results of different antioxidant assays and oxidation parameters in the present analysis, the ME of oat, groats and hull, coffee beans and Moringa oleifera, could be generally declared as the most effective antioxidant extracts. The antioxidant efficacy of the ME of Lawsonia alba and Iris germanica, although, appreciably high, was variable to a significant extent in the two substrate 


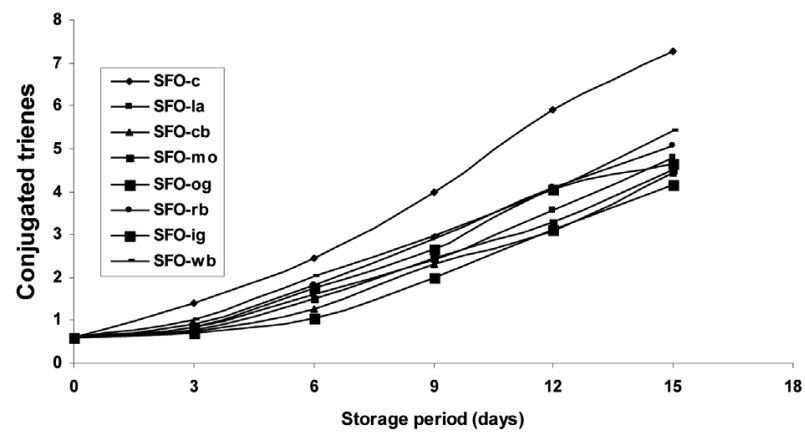

Figure $8 a$

Relative increase in conjugated trienes $\left({ }^{1 \%} \mathcal{E}_{1 \mathrm{~cm}}\left(\lambda_{268 \mathrm{~nm}}\right)\right.$ of SFO treatments under accelerated storage conditions

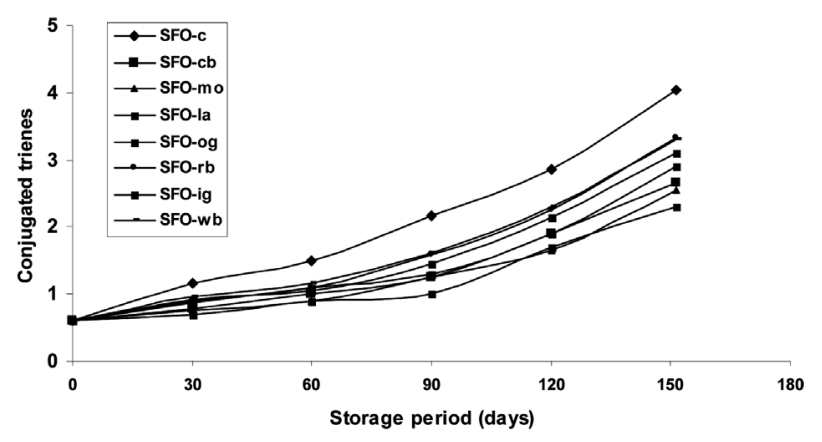

Figure 8b

Relative increase in conjugated trienes $\left({ }^{1 \%} \varepsilon_{1 \mathrm{~cm}}\left(\lambda_{268 \mathrm{~nm}}\right)\right.$ of SFO treatments under ambient storage conditions

oils, and, under accelerated and ambient storage as well. The antioxidant activity of rice bran was generally higher than wheat bran, however, it was variable to some extent in some cases. Findings from our present study are also supported from the literature, stating that plant extracts may sometimes exhibit contradictory antioxidant activity when used under different conditions (Economou et al., 1991).

The antioxidant activity of various extracts as investigated in the present analysis is due in part to the constituent natural antioxidant substances of plant organs. Relatively higher antioxidant activity of extracts from oat, groats and hulls might be attributed to the occurrence of a high amount of natural antioxidant phenolics (gallic, caffeic, ferulic acid etc) and avenanthramides (Peterson, 2001; Velioglu et al., 1998). A high antioxidant efficacy of coffee beans might be attributed to the high content of caffeic acid and other phenolics present in coffee beans. The presence of polyphenols of an antioxidant nature in coffee beans has already been reported by some researches (Plumb et al., 1999).

The potential antioxidant properties of rhizome of Iris germanica may be fully supported by the literature since the rhizome and leaves of this plant are found to be a rich source of flavonoids, ascorbic acid, vitamins and phenolics (Atta-ur-Rehman et al., 2000), which might show good antioxidant activity and thus protection for the oils during storage. The antioxidant effects of ME in the leaves of Lawsonia alba may be deemed on account of flavonoids, coumarins and gallic acid, present in the leaves of this plant (Handa et al., 1997).

The high antioxidant activity of Moringa oleifera leaf extract, as exhibited in the present study, could be attributed to the presence of various phenolic compounds. Siddhuraju and Becker, (2003) have also reported the antioxidant properties of various solvent extracts of the total phenolic constituents from leaves of the Drum Stick tree (Moringa oleifera Lam.). Similarly, the antioxidant activity of ME of wheat and rice bran could be attributed to the presence of a significant amount of caffeic, ferulic, gallic acids, and oryzanol, found biologically, which are considered to be good natural antioxidants (Shahidi, 1997).

\section{CONCLUSION}

It could be concluded from the results of the present investigation that some oxidation parameters of assessing in vitro antioxidant effectiveness might be rapid and convenient depending on storage conditions, nature of oil and extent of oxidation. A number of different methods may be necessary to adequately assess the in vitro antioxidant activity of a specific plant material. By combining the knowledge of different antioxidant assays and assessment of oxidation parameters in the present study, it can be asserted that the investigated plant materials are a viable source of natural antioxidants and might have potential as "nutraceuticals" for the preparation of functional foods. As Pakistan is rich in medicinally important flora, the meaningful exploitation of more indigenous plant materials and agricultural wastes is thus further recommended. An assessment of the toxicity and kinetic studies, as well as the function of these extracts in food and biological systems also needs to be investigated.

\section{ACKNOWLEDGEMENT}

The authors would like to sincerely thank Dr. M.I.Bhanger (Director CEAC, Jamshoro, Pakistan) for his kind assistance and guidance during the completion of this manuscript.

\section{REFERENCE}

Abdalla A E, Roozen J P. 2001. The effect of stabilized extracts of sage and oregano on the oxidation of salad dressings. Eur. Food Res. Technol. 212, 550-551.

Anwar F, Bhanger M I, Kazi T G. 2003a. Relationships of Rancimat and AOM values at varying temperatures for several oils and fats. J. Am. Oil Chem. Soc., 80, 151-155,

Anwar F, Bhanger M I, Yasmeen S. 2003b. Antioxidant activity of some natural extracts in corn oil. Advanced Research of Plant Lipids, Proceeding of 15-ISPL, May 12-17, 2002, Okazaki, Japan. Eds. N. Muarata, M.Yamada, I.Nishida et al., Kluwer Publishers Netherlands, pp. 24-27. 
Att-u-Rehman, Choudhary M I, Nure-e.Alam M, Ndognii PO, Badarchiin V. 2000. Pharm. Bull. 48, 738-779.

Bandoniene D, Pukalskas A, Venskutomis P R, Gruzdiene D. 2000. Preliminary screening of antioxidants of some plants extracts in rapeseed oil. Food Res. Int. 23, 785-791.

Economou K D, Oreopoulou V, Thomopoulos C D. 1991. Antioxidant activity of some plant extracts of the family Labiateae. J. Am. Oil Chem. Soc. 68, 109-113.

Emmons C L, Peterson D M. 1999. Antioxidant activity and phenolic contents of oat groats and hull. Cereal Chem. 76, 902-906.

Farag R S, Badei A Z M A, Baroty E. 1989. G.S.A. Influence of thyme and clove essential oils on cottonseed oil oxidation. J. Am. Oil. Chem. Soc. 66 , 800-804

Gheldof N, Engeseth N J. 2002. Antioxidant capacity of honey from various floral sources based on the determination of oxygen radical absorbance capacity and inhibition of in vitro lipoprotein oxidation in human serum samples. J. Agric. Food Chem. 50, 3050-3055.

Gheldof N, Wang X-H, Engeseth N J. 2003. Buckwheat honey increases serum antioxidant capacity in human. J. Agric. Food Chem. 5, 1500-1505.

Handa G, Kapil A, Sharma S, Singh J. 1997. Lawnermis acid: A new anticomplementry triterpenoid from Lawsonia Inermis. Ind. J. Chem. 38B, 2813-2815.

International Union of Pure and Applied Chemistry (IUPAC). 1987. Standard Methods for the Analysis of Oils, Fats and Derivatives, 7th revised and enlarged ed., Paquot, C., Hautfenne A., Eds.; Blackwell Scientific Publications, London, U.K.

Jeong S, Kim S, Kim D, Jo S, Nam K, Ahn D, Lee S. 2004. Effect of heat treatment on the antioxidant activity of extracts from citrus peels. J. Agric. Food Chem. 52, 3389-3393.

Kazuhisa Y. 2001. Oils and fats. Reito. 76, 405-409.

Laandrault N, Pouchert P, Ravel P, Gase F, Cros G, Teissedro P-L. 2001. Antioxidant activities and phenolic level of French wines from different varieties and vintages. J. Agric. Food Chem. 49, 3341-3343.

Liu S, Manson J E, Lee I M, Cole S R, Hennekens C H, Willett W C, Buring J E 2000. Fruit and vegetable intake and risk of cardiovascular disease: the women's health study. Am. J. Clin. Nutr. 72, 922-928.

McGinely L. 1991. Analysis and quality control for processing and processed fats. In: Analysis of Oilseeds, Fats and Fatty Foods, Eds.; Rossell, J.B.; Pritchard, J. L.R., Elsevier Applied Science, London, New York, pp. 460-470.

Metha R L, Joseph F Z, Yang S S. 1994. Ajwan as a source of natural lipid antioxidants, J. Agric Food Chem. 42, 1420-1422.
Metrohm Application Bulletin No. 204/ 1e. 1993. Oxidative stability of Oils and Fats-Rancimat Method; Mterohm A.G., Switzerland.

Mitsuda H, Yasumoto K, Iwami K. 1966. Antioxidant action of indole compounds during the autoxidation of linoleic acid. Eiyoto Shokuryo. 19, 210-214.

Osawa T, Namiki M A. 1981. A novel type of antioxidants isolated from leaf wax of eucalyptus leaves. Agric. Biol. Chem. 45, 725-739.

Peterson D M. 2001. Oat antioxidants. J. Cereal Sci. 33, 115-129.

Pezzuto J M, Park E J. 2002. Autoxidation and antioxidants In: Encyclopedia of Pharmaceuticals Technology2nd Edition, Vol. 1 Eds; Swarbrick, J and Boylan, J.C., Marcel Dekker, Inc., New York, pp.97-113.

Plumb G, Geoffrey W, Price K P, Williamson G. 1999. Antioxidant properties of flavonol glycosides from green beans. Redox Rep. 4, 123-127.

Saleem A, Ahotupa M, Pihlaja K, 2001. Total phenolics concentration and antioxidant potential of medicinal plants of Pakistan. Z. Naturforsch. 56, 973-978.

Shahidi F. 1997. Natural antioxidants: an overview, In: Natural Antioxidants, Chemistry, Health Effects and Applications, Ed. F. Shahidi, AOCS Press Champaign, Illinois, USA, pp.1-10.

Siddhuraju P, Becker K. 2003. Antioxidant properties of various solvent extracts of total phenolic constituents from three different agroclimatic origins of Drum stick tree (Moringa oleifera Lam.) leaves. J. Agric. Food Chem. 51, 2144-2155.

Velioglu, Mazza S G, Gao L, Oomah B D. 1998. Antioxidant activity and total phenolics in selected fruits, vegetables, and grain products. J. Agric. Food Chem. 46, 4113-4117.

Wang S-Y, Chang H-N, Lin K-T, Lo C-P, Yang N-S, Shyur L-F. 2003. Antioxidant properties and phytochemical characteristics of extracts from Lactuca indica. J. Agric. Food Chem. 51, 1506-1512.

Wyen D V, Takacsova M, Jakubik T, Dang M. 2000. Antioxidant effects of thyme in rape-seed oil, Biologia (Bratislava), 55, 277-281.

Yoon S H, Kim S K, Shin M G, Kim K H. 1985. Comparative study of physical methods for lipid oxidation measurement. J. Am. Oil Chem. Soc, 62, 1487-1489.

Yoshida H, Takagi S. 1999. Antioxidative effects of sesamol and tocopherols at various concentrations in oils during microwave heating. J.Sci. Food Agric. 79, 220-226.

Zuo Y, Wang C, Zhan J. 2002. Separation, characterization, and quantification of benzoic and phenolics antioxidants in American Cranberry fruit by GC-MS, J. Agric. Food Chem. 50, 3789-3794.

Recibido: Agosto 2004 Aceptado: Noviembre 2005 